\title{
Poesía y ficción en el Persiles: para una hermenéutica de la forma narrativa ${ }^{1}$ \\ Poetry and Fiction in Persiles: towards a Hermeneutics of Narrative Form
}

\section{Luis Galván}

Universidad de Navarra, GRISO

ESPAÑA

Irgalvan@unav.es

[Hipogrifo, (issn: 2328-1308), 6.2, 2018, pp. 101-116]

Recibido: 13-08-2018 / Aceptado: 18-10-2018

DOI: http://dx.doi.org/10.13035/H.2018.06.02.10

Resumen. Este artículo plantea un estudio del Persiles en el marco de la teoría de la ficción. Se examinan algunas declaraciones autorreferenciales y metaliterarias de la novela, así como la configuración de su argumento, teniendo además en cuenta algunos antecedentes, en particular el Quijote. Los resultados abonan la propuesta de subordinar el análisis semántico de la ficción, que opera con las categorías de verdadero y falso, al análisis de la elaboración verbal y su efecto comunicativo. La narrativa ficcional responde al problema de cómo captar la atención y mantenerla, haciendo que se reconozca la pertinencia de lo que se va contando. En conclusión, se ha de pensar la narratividad en términos hermenéuticos y cognoscitivos: un dinamismo orientado hacia un final que se comprende como cumplimiento o plenificación de una trayectoria.

Palabras clave. Ficción; narratividad; hermenéutica; cognitivismo; muerte; Cervantes; Persiles; Quijote.

Abstract. This paper deals with Cervantes's Persiles in the frame of a theory of fiction. After a survey of its antecedents (especially Don Quixote), self-referential and metaliterary commentaries in Persiles, as well as of its plot, are examined. The results suggest that the semantics of fiction, which employs the categories true/

1. Este trabajo ha sido realizado en el marco del proyecto de investigación «Actualidad de la hermenéutica» (FFI2013-41662-P), financiado por el Ministerio de Economía y Competitividad y los Fondos Estructurales de la Unión Europea (FEDER) para el período 2014-2017. 
false, should be made dependent on the analysis of the verbal configuration and communicative effect of narrative. Fictional narrative faces the task of engaging the audience's attention and showing the relevance of the story's development. Thus, narrativity should be conceived of in hermeneutical and cognitive terms: a drive towards an end that has to be understood as the fulfilment or completion of a path.

Keywords. Fiction; Narrativity; Hermeneutics; Cognitivism; Death; Cervantes; Persiles; Quijote.

\section{POESÍA Y FICCIÓN}

El presente trabajo pretende tomar Los trabajos de Persiles y Sigismunda como ocasión para ilustrar y anudar dos líneas de reflexión teórica, una sobre la ficcionalidad y la otra sobre la forma narrativa². El Persiles es idóneo para ello por varias razones. Primero, porque aparece en una época en que el concepto de ficción se está redefiniendo y se está convirtiendo en rasgo esencial de lo que hemos acabado por llamar literatura ${ }^{3}$. Por un lado, la palabra ficción se introduce en las lenguas románicas a partir del Humanismo, y se refiere sobre todo a la mitología grecorromana; luego se generaliza para otros contenidos literarios. Esto tiene dos consecuencias: que ficción se hace más o menos equivalente de 'fábula' y 'mentira', y que se trata de justificar su cultivo con algún otro tipo de verdad; habitualmente, interpretaciones alegóricas o morales. Por otro lado, la literatura contemporánea, con ficciones de nuevo cuño como el Persiles, problematiza la autorreferencialidad del lenguaje: que un texto diga de sí mismo que es verdadero no garantiza su veracidad. Aunque durante un tiempo se recurre a artificios como el manuscrito encontrado, típico de los libros de caballerías, parodiado en el Quijote y solo de pasada mentado en el Persiles, al final la única validación para los lectores provendrá de la verosimilitud. Esto lo declara en el ámbito teórico un contemporáneo de Cervantes, Alonso López Pinciano en la Filosofía antigua poética, recuperando ideas de Aristóteles, y en la práctica se encuentra ya en el Quijote y, de otra manera, que veremos con mayor detalle, en el Persiles ${ }^{4}$.

La segunda razón de la idoneidad del Persiles es que Cervantes en general y esta novela en particular ofrecen un elemento de reflexión metaliteraria que facilita la tarea a quien persigue una cuestión teórica, como es el caso. Quede advertido, sin embargo, que no pretendo rastrear la teoría o preceptiva literaria y novelesca de Cervantes con un planteamiento más o menos historicista, sino partir de

2. Una versión preliminar de este trabajo se presentó en el congreso internacional «El Persiles en su IV centenario» (Universidad de Navarra, diciembre de 2017). Agradezco a Carlos Mata la oportunidad de participar en dicha actividad, tanto más cuanto esta no es, estrictamente, una investigación sobre el Persiles. Por esta última razón, se disculpará que no cite ni discuta de manera sistemática la bibliografía existente, aunque mencionaré algunos estudios relevantes para las cuestiones que trato.

3. He explicado este proceso en varias ponencias en curso de publicación, en los congresos: I Jornadas en torno a Sebastián de Covarrubias (Cuenca, octubre de 2017), Vidas en armas (Huelva, abril de 2018) y VII congreso internacional de la SEMYR (Salamanca, septiembre de 2018).

4. Ver Pozuelo Yvancos, 1993, pp. 15-62; Lozano Renieblas, 1998, pp. 120-124. 
una problemática teórica y ver qué datos ofrece el Persiles para precisarla y quizá, idealmente, resolverla 5 .

Creo que el Persiles abona la propuesta -que sugiere la etimología misma- de separar el concepto de ficción del de mímesis, con el que frecuentemente se relaciona, y entenderlo en términos de poíesis ${ }^{6}$. En otros términos, se trata de subordinar la semántica de la ficción, que opera con las categorías de verdadero y falso, a los aspectos de la elaboración verbal y su efecto comunicativo (o llámese dimensión pragmática, o retórica, o interpersonal). Algo de esto entendió Cervantes, cuando, a propósito del largo relato que hace Periandro/Persiles de sus andanzas, entre otras cosas escribe:

si no se arrimara la paciencia al gusto que tenían Arnaldo y Policarpo de mirar a Auristela, y Sinforosa de ver a Periandro, ya la hubieran perdido escuchando su larga plática, de quien juzgaron Mauricio y Ladislao que había sido algo larga y traída no muy a propósito, pues, para contar sus desgracias propias, no había para qué contar los placeres ajenos. Con todo eso, les dio gusto y quedaron con él, esperando oír el fin de su historia, por el donaire siquiera y buen estilo con que Periandro la contaba ${ }^{7}$.

En estas compendiosas líneas salen al relucir muchos de los temas que debe abordar una teoría de la ficción y la narración, y que procuraré conectar en las páginas que siguen: el problema de la elongación del turno de palabra, el de la pertinencia o relevancia de los acontencimientos narrados, el del suspense o curiosidad por el final, el del estilo y el de la copresencia de emisor y receptor.

\section{EL PROBLEMA DE LA FORMA}

Según decía al principio, el problema de la ficción ha de relacionarse con el de la forma narrativa, sin confundirse con él. En efecto, el Persiles los conecta y los distingue, en el siguiente comentario autorial acerca de lo que se va contando:

Es excelencia de la historia que cualquiera cosa que en ella se escriba puede pasar, al sabor de la verdad que trae consigo; lo que no tiene la fábula, a quien conviene guisar sus acciones con tanta puntualidad y gusto, y con tanta verisimilitud que, a despecho y pesar de la mentira, que hace disonancia en el entendimiento, forme una verdadera armonía (III, 10, p. 343).

5. Sigo en esto el planteamiento de José María Pozuelo Yvancos. Sin embargo, aun siendo tan valioso su magisterio, me parece preferible evitar la confusión que sugiere cuando dice que hay que estudiar no tanto «la teoría "presente" en el Quijote» cuanto «la poética de la ficción "del" Quijote»; pues este libro es «una novela y [...] simultáneamente una poética de la ficción novelesca» (Pozuelo Yvancos 1993, pp. 26-27). Sencillamente, el Quijote y el Persiles no son «poéticas» o teorías, sino prácticas de la ficción, y lo que propongo es hacer la teoría de esa práctica.

6. Ver Galván, en prensa.

7. Cervantes, Persiles, ed. Avalle-Arce, II, 11, p. 217. En lo sucesivo indicaré en el texto el libro y el capítulo; cuando se trate de una cita literal, añadiré el número de página. Lo mismo haré en las referencias al Quijote. 
Con razón o sin ella, que en eso no me meto ahora, el autor de esas líneas da a entender que la verdad de un hecho es razón suficiente para contarlo y para que interese, mientras que la falta de aquella ha de compensarse mediante recursos compositivos. Añado yo que uno de esos recursos, el más excelente en el sentir de Aristóteles, es la elaboración de un argumento que conecte los acontecimientos con una causalidad necesaria o verosímil y los desenvuelva desde un principio hasta un final que se reconozcan como tales.

Pues bien, pronto aparece el problema de cómo distinguir entre la conexión que tienen los acontecimientos por sí y la que les aporta la forma argumental. Aristóteles habla de la «imitación de una acción completa y entera [...]. Es entero lo que tiene principio, medio y fin. Principio es lo que no sigue necesariamente a otra cosa, sino que otra cosa le sigue por naturaleza en el ser o en el devenir. Fin, por el contrario, es lo que por naturaleza sigue a otra cosa, o necesariamente o las más de las veces, y no es seguido por ninguna otra. Medio, lo que no solo sigue a una cosa, sino que es seguido por otra» ${ }^{8}$. Nótese que estas son partes de la acción; en otro lugar hace una bipartición, en «nudo y desenlace» (1455b24), y estas parecen ser partes de la tragedia o del argumento, no de la acción (1456a7-8). Por otro lado, la amalgama es clara cuando, para explicar la diferencia entre los argumentos simple y complejo, explica en realidad diferencia entre las acciones, «a las cuales imitan» los argumentos (1452a12-14).

Cervantes también fue sensible a este problema, que formuló en dos ocasiones al menos. Cuando Ginés de Pasamonte cuenta a don Quijote que ha escrito un libro sobre su propia vida, este pregunta si está acabado, y aquel responde: «¿Cómo puede estar acabado [...], si aún no está acabada mi vida?» (I, 22). Con algo mayor prolijidad, y evidente conexión con la explicación de Aristóteles recién citada, en el Persiles se habla de un poeta que concibió el deseo de componer una obra teatral sobre los trabajos de Periandro y Auristela,

pero no acertaba en qué nombre le pondría: si le llamaría comedia, o tragedia, o tragicomedia, porque si sabía el principio, ignoraba el medio y el fin, pues aun todavía iban corriendo las vidas de Periandro y de Auristela, cuyos fines habían de poner nombre a lo que dellos se representase (III, 2, p. 285).

Veamos ahora que esta es una cuestión insuficientemente resuelta en la teoría literaria, que incurre, quizá inadvertidamente, en un círculo vicioso. A riesgo de simplificar, puede decirse que el fundamento de la narratología está en la distinción entre el discurso o texto narrativo y los contenidos («acontecimientos» o «acciones») representados por él; evidentemente, la distinción es análoga a la saussureana de significante y significado?.

8. Poética, 1450b25-32.

9. Ver, por ejemplo, Ryan, 2007, p. 26. La distinción se especifica y matiza con diversas parejas de términos: fable/sujet, histoire/discours, story/plot. Queden aparte ahora posibles triparticiones: histoire/récit/ narration, acción/relato/discurso, etc. (ver Genette, 1972, pp. 72-73; García Landa, 1998). 
Ahora bien, pronto nos encontramos a continuación con que los acontecimientos relatados suelen concebirse como pedazos del mundo real; principio, medio y fin lo son de las acciones, no de su forma narrativa. El caso es que saber qué vale como principio y qué como final requiere comprender la acción como un comportamiento con sentido, y no mera sucesión de actos y estados. Y cuando buscamos una explicación en la teoría y filosofía de la acción, nos encontramos con que se dice que es la forma narrativa lo que orienta la acción y da sentido a la serie de acontecimientos que constituye la vida de cada persona. Cada vida entra en la preexistente red de las relaciones humanas; y el conflicto de innumerables voluntades e intenciones impide, por lo general, que las acciones individuales alcancen su propósito. Por esto, cada uno es sujeto de su vida en el doble sentido de agente y paciente, pero nadie es autor o productor de su propia vida entendida como relato, sino, a lo sumo, coautor. La acción y la historia ocultan su sentido al sujeto, y lo revelan a la mirada retrospectiva del narrador. Así pues, los intentos de dar forma, coherencia y sentido al devenir humano se basan en atribuir a la vida real las propiedades de los relatos, que sí son hechos por un autor con una forma determinada ${ }^{10}$. En este punto resulta claro que se ha formado un círculo vicioso, una vez que la narratología remite a la «acción completa» y la teoría de la acción remite a la narrativa.

Vengamos a la cuestión del final de la vida, que aparecía en las anteriores citas del Quijote y el Persiles. Walter Benjamin considera que tiene un papel fundamental en la experiencia de lectura de la ficción literaria. Cuando comienza un relato, el lector se interesa por unos personajes, y se abre la perspectiva de llegar a un final que bien puede ser la muerte; así pues, la cuestión clave es: «¿cómo le dan a conocer que la muerte ya los está esperando, una muy concreta, y en un lugar muy concreto?» ${ }^{11}$. Ese "cómo» es el propio trabajo del texto, el hiato entre comienzo y fin, origen y muerte, abierto por la dilación y la diferencia mediante una serie de transformaciones. El comienzo se va trasformando en final a través de varias fases, cada una de las cuales conserva algo igual y aporta algo diferente. Este juego de repetición y novedad produce una forma perceptible y reconocible, y una orientación hacia un final y una muerte que se reconozcan como apropiados ${ }^{12}$. Ahora bien, también en este campo se confunden las aplicaciones de lo que Derrida llama la «pulsión» o «ley de lo propio» en la narrativa y en la vida real13. No podía ser de otra manera, puesto que la muerte, como observaba Aristóteles, es un extremo o límite (éskhaton, péras), pero no una finalidad o extremo-para-lo-cual (télos, éskhaton hou héneka) ${ }^{14}$; así pues, el convertirla en finalidad requiere cierta elaboración.

Para escapar de la circularidad, sugiero, como decía al principio, que es necesario subordinar el aspecto semántico de los relatos ficcionales a su aspecto comunicativo. La cuestión la ha planteado con vigor Mary-Louise Pratt, al señalar

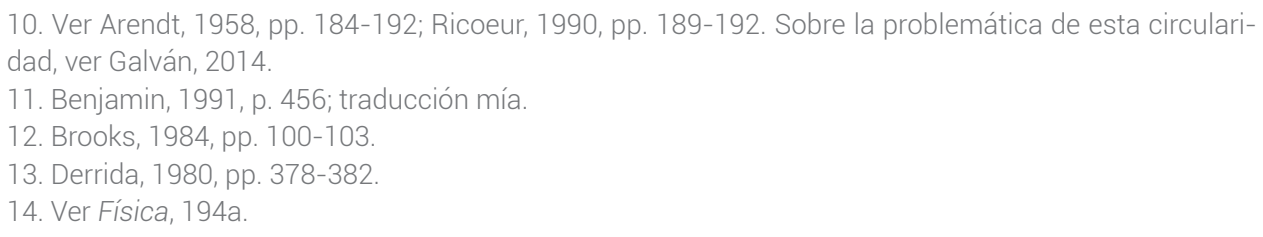


que las características del discurso literario han de entenderse a partir de las características de la situación comunicativa literaria; en particular, de la deuda que contrae un autor con su audiencia porque esta se sujeta voluntariamente a su prolongado uso de la palabra. El análisis de Pratt es demasiado general, pero se puede ganar algo de precisión recurriendo a la propuesta postestructuralista de Roland Barthes ${ }^{15}$. Barthes explica que en un texto narrativo se entrecruzan dos códigos de carácter dinámico, que proyectan en relato hacia delante, hacia el final: la secuencia de acontecimientos (código de las acciones o proairético), y la formulación de un problema más la búsqueda de la solución (código de los enigmas o hermenéutico). Ahora bien, considera que las acciones y su secuencia son contingentes y convencionales; su unidad surge artificiosamente en la lectura, por el impulso de agrupar un conjunto de datos bajo un esquema general, y de entrever una lógica verosímil en su encadenamiento. De acuerdo con esta descripción, el código de las acciones parece reducible al de los enigmas, pues consiste en preguntar qué es lo que sucede, y por qué. Barthes parece considerar el código de los enigmas inherente a la naturaleza del lenguaje: el problema y su solución tienen la estructura de sujeto y predicado; y su impulso es la búsqueda de una verdad que satisfaga la expectativa, que cumpla y cierre. La vida del relato consiste en ofrecer un problema y prometer su resolución pero posponerla, desviar y distraer al lector, hasta el desvelamiento final. Así pues, los componentes de la serie hermenéutica son la tematización del objeto del enigma, el planteamiento y la formulación del enigma, la petición o promesa de respuesta, la posposición del cumplimiento de esta mediante el engaño, el equívoco, el bloqueo, la suspensión, la respuesta parcial; al cabo, la revelación completa. En esencia, relatar, referir, es dilatar, diferir, y leer relatos es advertir la existencia de un enigma, admitir la necesidad de las dilaciones, y reconocer el final del texto como solución apropiada.

Una consecuencia de esto sería la conveniencia de relativizar, ya que no anular, la diferencia entre lo que se llamó «forma temporal» y «forma espacial», o en términos no mucho más claros, «relato mitológico» y «relato ideológico» ${ }^{16}$. El primero consiste en la ordenación temporal-causal, mientras que el segundo dispone acciones aisladas, quizá de personajes diferentes, que se reconocen como ejemplos de una misma regla o idea abstracta. Si es cierto lo que proponen Benjamin, Barthes y Brooks, semejante reconocimiento también tiene un papel en el orden temporal-causal.

Se concluye de lo anterior que la estructura más relevante para la actividad de narrar no es la de los acontecimientos en el mundo, sino la del conocimiento. Pero esto no significa sustituir sin más la narratología estructuralista por la cognitivista. Como señala Meir Sternberg, el enfoque cognitivista retorna demasiadas veces al mundo -en términos de «conocimiento del mundo»-y se olvida del conocimiento del lenguaje ${ }^{17}$. Lo que hace falta es analizar la dinámica cognoscitiva de suspen-

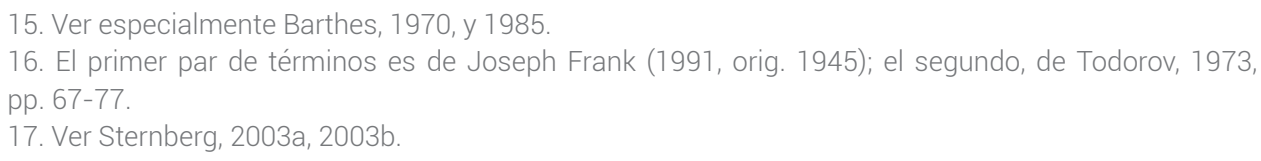


se, curiosidad y sorpresa, generada por el libre juego del tiempo representado y el tiempo de representación.

Una última observación para cerrar este apartado teórico: este enfoque, si se desarrolla en su radicalidad, podrá recuperar una cuestión abandonada por el estructuralismo: la teleología propia de la intencionalidad de los actos de conciencia. El «mero pensar», según Edmund Husserl, es insatisfactorio; desencadena un dinamismo que alcanza la satisfacción en la intuición de lo pensado. El cumplimiento o satisfacción son una vivencia de la identidad entre los objetos del primero y el segundo acto, pero una identidad que incluye un incremento, una «preeminencia» del segundo ${ }^{18}$.

\section{ALgunOS ANTECEDENTES}

Quisiera mostrar ahora algunos antecedentes del Persiles en el uso de la muerte como elemento organizador del relato de principio a fin. En primer lugar, el motivo de la muerte tiene un papel decisivo en la organización de los libros de caballerías $^{19}$. Hay dos patrones básicos. El más frecuente es el retorno cíclico de cuasimuertes y cuasi-resurrecciones: el caballero corre grave peligro de morir a causa de combates, tormentas, accidentes, penas de amor, encantamientos; no rara vez se lo llora como muerto; pero siempre, o casi siempre, se sobrepone y retorna a la vida. Este es el dinamismo básico de la serie de los Amadises según la versión que dan Rodríguez de Montalvo y Feliciano de Silva, un dinamismo que se proyecta indefinidamente hacia el futuro porque los encantamientos de Urganda la Desconocida liberan a Amadís de Gaula y a muchos otros personajes de la necesidad de envejecer; es decir, no solamente escapan a la muerte accidental sino también a la natural. La misma configuración tiene Tirante el Blanco, con la diferencia de que el último asalto es mortífero: el caballero sucumbe al repentino dolor de costado. El segundo patrón, menos corriente, ritma el relato según el proceso natural de extinción de la vida. Un ejemplo claro es Lisuarte y Muerte de Amadís (1526) de Juan Díaz. Comienza con Amadís de Gaula en la cumbre de su poder, capaz de dirigir la guerra contra los infieles y combatir él mismo, hasta la mitad del libro. Poco después Urganda profetiza su muerte y, en efecto, sufre algunas derrotas que lo hunden en la tristeza y la enfermedad, entra en fase terminal, recibe los últimos sacramentos y muere, a lo que siguen el duelo, el sepulcro, las exequias y el traslado de sus restos a un monasterio. Análogamente, el Palmerín de Inglaterra está jalonado por el envejecimiento y extinción la primera generación caballeresca, presentada en Palmerín de Olivia y Primaleón. Primero muere Trineo, emperador

18. Investigaciones lógicas, VI, caps. 1-3, §§ 8, 10, 16 (Husserl, 2006, vol. 2, pp. 621-627, 646). Husserl pone en un extremo las intenciones «significativas», por ser especialmente «vacías» $y$ «necesitadas de plenitud»; en el otro, algunos actos especialmente adecuados para funcionar como cumplimiento: la «plenitud de la representación», cuyo ideal solamente es alcanzado por la «percepción adecuada», con el «máximo de extensión, de vivacidad y de realidad, justamente como aprehensión del pleno y total objeto mismo» (investigación VI, cap. 3, § 23; en 2006, vol. 2, pp. 653-659). Para una aplicación de estos conceptos a otros problemas de la literatura y ficción del siglo XVII, ver Galván, 2011.

19. Resumo aquí los análisis expuestos en Galván, 2009 y 2012. 
de Alemania y cuñado de Palmerín de Oliva; después, Fadrique, rey de Inglaterra, su consuegro. El propio Palmerín de Oliva va decayendo a lo largo del libro: está envejecido, ya no puede justar, espera la muerte, llora, se trastorna por las malas noticias, queda inválido, y muere de la impresión cuando un enorme ejército turco ataca Constantinopla. Este acontecimiento da el tono para el último acto de la novela: el ejército constantinopolitano se cubre de luto, quema su propia ciudad para luchar más desesperadamente, y logra la victoria pero con grandísimas pérdidas, que dejan a los supervivientes con ganas de morir.

El segundo antecedente es el Quijote. Entre los extremos de pensar que la muerte del protagonista es consecuencia sobrevenida del apócrifo de Avellaneda - «una muerte literaria por celos» la llamó Thomas Mann20 - o afirmar que «el libro entero ha sido escrito para esta escena, para la muerte de don Quijote» - como hizo Borges $^{21}$-, hay razones para inclinarse a lo segundo, por motivos tanto internos al texto como externos ${ }^{22}$. Sería muy largo, y fuera del propósito de este trabajo, desgranar la isotopía de la muerte en todos los estratos del Quijote. Basten unas pinceladas para señalar que sus menciones y anticipaciones a lo largo del texto hacen de esta novela un caso señero para estudiar el papel del final en la configuración global de la narrativa y en el dinamismo teleológico de sus componentes y niveles. Nótese que, desde la perspectiva del narrador, don Quijote está muerto desde la primera frase: «no ha mucho tiempo que vivía» $(1,1)$; y, como personaje que frisa los cincuenta años, es ya un viejo con corta esperanza de vida (así se lo hace ver su sobrina, en II, 6). Por otro lado, él mismo declara tener hecho testamento (I, 20), considera la posibilidad de acabar como un caballero muerto de calenturas pestilentes que llevan a enterrar $(I, 19)$. Además, la última aventura de la primera parte lo deja como muerto - «no bullía pie ni mano»-, hasta el punto que Sancho pronuncia un lamento fúnebre $(1,52)$.

La segunda parte empieza prometiendo desde el prólogo a don Quijote «finalmente muerto y sepultado», lo que orienta las expectativas con mayor determinación hasta la última escena. Esa determinación del autor se entrelaza con la del personaje, que dice: «Caballero andante he de morir» (II, 1), porque semejante muerte le garantiza la fama y la salvación (II, 6, 24). Esa voluntad de tener una muerte propia de caballero procura ejecutarla don Quijote en dos ocasiones al menos. En la aventura de los leones, dice a Sancho: «si aquí muriere, ya sabes nuestro antiguo concierto: acudirás a Dulcinea, y no te digo más» (II, 17). Como no sucede así, re-

20. Mann, 2002 (orig. 1934), p. 84.

21. Borges, 1956, p. 36.

22. El trabajo de síntesis de Fernández (2006) exime de la necesidad de revisar toda la bibliografía que analiza la muerte de don Quijote, pero vale la pena mencionar al menos los trabajos de Lo Ré, 1989, y Cull, 1992. En cuanto a lo que llamo motivos externos, un examen de los libros de caballerías hace dudar de que la muerte de don Quijote responda al deseo de evitar continuaciones, pues de hecho en la tradición caballeresca ese recurso no había servido. Dejando aparte que Rodríguez de Montalvo probablemente modificó una versión primitiva del Amadís que incluía la muerte del caballero, ciertamente se puede constatar que Juan Díaz hizo morir a Amadís y sin embargo Feliciano de Silva escribió nuevas continuaciones, desentendiéndose de ello; y que Palmerín de Olivia muere al final del Primaleón y reaparece vivo en su continuación, Palmerín de Inglaterra. 
itera su intención en casa de los duques: «caballero soy y caballero he de morir» (II, 32), y con tal resolución es como sufre la derrota ante el Caballero de la Blanca Luna:

Dulcinea del Toboso es la más hermosa mujer del mundo, y yo el más desdichado caballero de la tierra, y no es bien que mi flaqueza defraude esta verdad. Aprieta, caballero, la lanza, y quítame la vida, pues me has quitado la honra (II, 64).

Este acontecimiento, alineado con el final de la primera parte, compone una estructura repetitiva de peligro y supervivencia típica de los libros de caballerías. Sin embargo, la diferencia entre estos libros y el Quijote es que aquí el personaje tiene el propósito de morir, de tal modo que la supervivencia frustra su voluntad. La negativa del de la Blanca Luna despoja en última instancia a don Quijote de la posibilidad de la muerte que él ha considerado propia de su condición de caballero. Así pues, el personaje queda entregado a la simple degeneración física y psíquica, que experimenta con pasividad (II, 59, 74).

Si añadimos a todos estos acontecimientos las muchas ocasiones en que los personajes o el narrador hablan de la muerte, ${ }^{23}$ encontramos, en primer lugar, una isotopía que no solamente contribuye al mero ritmo lineal del texto sino que también enlaza el principio y el final mediante una serie de repeticiones con variaciones. En segundo lugar, se configura un itinerario interior del personaje de don Quijote que lo prepara para encontrase con su verdadera identidad en una muerte que no es la que él creía propia, sino la que verdaderamente lo era. En tercer lugar, se justifican la situación narrativa que se instaura desde el comienzo de la primera parte y la intención del autor que habla en el prólogo de la segunda. ¿Por qué introducir al personaje cuando ya está próximo a morir («cincuenta años») y adoptar la perspectiva de que ya ha muerto («no ha mucho que vivía»)? ¿Por qué habría de querer el autor la muerte del personaje? En cierta manera, las preguntas están de más porque el Quijote no es más que eso: que Alonso Quijano al principio está para morir y al cabo muere. Entre medias, su modo de aguardar la muerte, un enorme bucle que da testimonio del poder y la futilidad de la voluntad.

\section{LA MUERTE Y LO PROPIO EN LOS TRABAJOS DE PERSILES Y SIGISMUNDA}

Vengamos en fin al Persiles para analizarlo desde la perspectiva que hemos ganado con los escarceos precedentes. Alguno podrá objetar que tanto recalcar la muerte es impertinente en relación con el Persiles, pues esta novela se sitúa en una tradición y género que no tiene ese final en el horizonte, sino más bien la reunión de los enamorados. Sea como fuere, no por eso se oblitera la muerte en esta novela. Juan Bautista Avalle-Arce ha hecho el siguiente recuento:

Un hojear rápido del Persiles deja un saldo de muertes extraordinario. Para mencionar algunas, nada más, allí mueren Cloelia, Manuel de Sousa Coutiño, Taurisa y sus dos enamorados, Rosamunda, Clodio, Cenotia, don Diego de Parraces, el conde marido de Constanza, el conde Domicio, el robador de Feliz Flora, el viejo

23. Por ejemplo, en II, 7, 11-12 (carro de las Cortes de la Muerte), 14, 20, 53. 
Castrucho, Ortel Banedre, Pirro y Maximino, sin contar las numerosas muertes de personajes anónimos, o las hecatombes generales, como la de la isla Bárbara ${ }^{24}$.

Avalle-Arce ofrece una interpretación ideológica de este hecho textual: la muerte favorece la universalización y la abstracción de la experiencia humana ${ }^{25}$. Pero hay otro aspecto importante, relacionado con una cuestión formal que también ha señalado este crítico: en el Persiles Cervantes «va atando los cabos sueltos y convirtiéndolos en apretado haz» para evitar las «formas abiertas» que favorecen la libertad especulativa del lector ${ }^{26}$. Pues bien, ¿qué forma de atar cabos más segura que matar al personaje? ¿Pero cómo hacerlo si las convenciones del género son otras?

Veamos, entonces, cómo la muerte no es solo cuestión de contenido sino también de configuración narrativa, incluso en el Persiles, y precisamente en la forma de muerte propia. Efectivamente, el primer capítulo ya presenta al protagonista considerando el suicidio ${ }^{27}$, y sacudido entre los peligros de morir sacrificado, asaeteado, o anegado por la tormenta. No es raro que poco más tarde, cuando recibe una ayuda inopinada, teme que no valdrá más que para «dilatar nuestra muerte» (I, 4, p. 70). En cuanto a Auristela, también sufre tantas desventuras que invoca la muerte para ponerles fin $(1,20)$. Por otro lado, encontramos en la primera parte dos muertes enteramente apropiadas: la muy cristiana de Cloelia $(1,5)$ y la de Manuel de Sosa, propia de enamorado, noble y cristiano (I, 10-11). Cuando más tarde vemos la muerte de dos caballeros en desafío y de una doncella enferma (I, 20), empezamos a tener la impresión de estar ante un repertorio.

La segunda parte se abre con otra tormenta que amenaza con matar a todos (II, 1), y luego se amplía el muestrario con la muerte accidental de Clodio (II, 4) y la ejecución de Cenotia (II, 17). En la tercera parte, una vez los personajes han llegado a tierra y se mueven por países civilizados, sigue habiendo peligros de muerte para los protagonistas. En Francia, Persiles cae desde una torre y el golpe lo deja casi sin vida, tanto que Sigismunda lo creyó muerto (III, 14). En Roma, la cortesana Hipólita, enamorada de Persiles, hace un hechizo que va consumiendo a Sigismunda (IV, 9), mientras que el rufián de aquella da a Persiles una puñalada de apariencia mortal (IV, 13).

Como si no pudiera faltar una muerte para concluir la novela, Cervantes se saca, como dicen, de la manga a un hermano de Persiles que llega enfermo a Roma, coincidiendo con la antedicha puñalada:

Habíase partido Magsimino con intención de llegar a Roma a curarse con mejores médicos que los de Terrachina, los cuales le pronosticaron que antes que en Roma entrase le había de saltear la muerte [...]. En efeto, frontero del templo de San

24. Avalle-Arce, 1975, p. 62.

25. Avalle-Arce, 1975, pp. 64-65. Ver otros desarrollos de Avalle-Arce en 1973, pp. 206-212, y 1989. No es posible abordar aquí la cuestión de la ideología del Persiles, y tanto menos con el nivel de sofisticación que ha puesto Nerlich (2005).

26. Avalle-Arce, 1975, p. 69.

27. «Bien querría yo no morir desesperado, a lo menos, porque soy cristiano; pero mis desdichas son tales, que me llaman y casi fuerzan a desearlo» (I, 1, p. 52). Entiéndase: «Desesperarse, es matarse de cualquier manera por despecho» (Covarrubias, Tesoro, s. v.). 
Pablo, en mitad de la campaña rasa, la fea muerte salió al encuentro al gallardo Persiles y le derribó en tierra, y enterró a Magsimino (IV, 14, p. 474).

Y esta muerte abre el camino al final propio de los protagonistas, pues la cita continúa así:

... el cual, viéndose a punto de muerte, con la mano derecha asió la izquierda de su hermano y se la llegó a los ojos, y con su izquierda le asió de la derecha y se la juntó con la de Sigismunda, y con voz turbada y aliento mortal y cansado dijo:

-[...] Aprieta, joh hermano!, estos párpados y ciérrame estos ojos en perpetuo sueño, y con esotra mano aprieta la de Sigismunda, y séllala con el sí que quiero que le des de esposo, y sean testigos de este casamiento la sangre que estás derramando y los amigos que te rodean [...].

Estas palabras, tan tiernas, tan alegres y tan tristes, avivaron los espíritus de Persiles, y, obedeciendo al mandamiento de su hermano, apretándole la muerte, con la mano le cerró los ojos, y con la lengua, entre triste y alegre, pronunció el sí y le dio de ser su esposo a Sigismunda (IV, 14, p. 474).

Hay razones, pues, para decir que la muerte, aunque esté tan presente en el Persiles, no es determinante para su argumento. Esto desplaza la cuestión desde lo específico de la muerte hacia lo más general de la propiedad: ya que los personajes no alcanzan una muerte propia o impropia, ¿cómo de propio es su emparejamiento y matrimonio?

Vemos entonces que, como tenían que escapar de la muerte, así también tenían que evitar los emparejamientos impropios. Pretenden casarse con Sigismunda el rey de la isla bárbara, el príncipe Arnaldo, el rey Policarpo y el duque de Nemours, mientras que Persiles ha de evitar los requerimientos de la princesa Sinforosa y la cortesana Hipólita. En esta perspectiva, los muchos emparejamientos que hay en la novela son, como las muchas muertes, un repertorio de posibilidades ${ }^{28}$, que van desde el descoco de Rutilio, Rosamunda y la mujer de Talavera hasta la renuncia al matrimonio para meterse monja de la portuguesa Leonora - que hace morir de pena a Manuel de Sosa-, pasando por la idea de casar a Clodio con Rosamunda para castigo mutuo $(\mathrm{I}, 14)$, las desventuras caballerescas de Renato y Eusebia, la inocencia de Feliciana y Rosanio, la simplicidad natural de Tozuelo y Cobeña, la criminosidad de Bartolomé y la talaverana y la industria de Agustina y Contarino y de Isabela Castrucho y Andrea Marulo.

Por una parte, este catálogo se deja ordenar conforme a la «cadena del ser» que Avalle-Arce ha invocado para interpretar otros aspectos del Persiles. Por otra parte, ejerce cierta influencia sobre las expectativas de conclusión de la peripecia, sobre todo cuando parece que Sigismunda se dispone a tomar por modelo una de esas parejas, la de Leonora y Manuel, diciendo a Persiles:

28. Con esto generalizo la idea de repertorio de tres modos de vida que describió Avalle-Arce (1975, pp. 73-87). 
Querría agora, si fuese posible, irme al cielo, sin rodeos, sin sobresaltos y sin cuidados, y esto no podrá ser si tú no me dejas la parte que yo misma te he dado, que es la palabra y la voluntad de ser tu esposa. Déjame, señor, la palabra, que yo procuraré dejar la voluntad, aunque sea por fuerza: que, para alcanzar tan gran bien como es el cielo, todo cuanto hay en la tierra se ha de dejar, hasta los padres y los esposos. Yo no te quiero dejar por otro; por quien te dejo es por Dios, que te dará a sí mismo, cuya recompensa infinitamente excede a que me dejes por él (IV, 10, p. 459).

El problema es si esto constituye un final propio para el relato. Considerando en abstracto el género hay que contestar que no, porque es de rigor la reunión feliz de los amantes; pero el Persiles en concreto ha adelantado mucho para abrir esta otra posibilidad. Se diría que la llegada del hermano de Persiles, su oportuna muerte y sus últimas palabras, que he citado arriba, son un recurso ex machina para hacer volver el argumento a su cauce genérico ${ }^{29}$.

Hasta aquí he considerado el código proairético del Persiles: si los protagonistas van a morir o se van a casar. Es hora de pasar al código hermenéutico: ¿qué enigma encierran? El primero y más banal es el de quiénes son el Persiles y la Sigismunda anunciados en el título, porque nada se sabe de ellos hasta bien entrado el segundo libro, cuando el protagonista exclama: «¿Qué reinos ni qué riquezas me pueden a mí obligar a que deje a mi hermana Sigismunda, si no es dejando de ser yo Persiles? - En pronunciando esta palabra, se mordió la lengua, y miró a todas partes a ver si alguno le escuchaba» (II, 6, p. 185). Más aún, este Periandro/Persiles y esta Auristela/Sigismunda, ¿son hermanos? Así lo dicen no solamente en público (I, 2, 23, etc.), lo que podría entenderse como disimulación, sino también hablando entre ellos a solas, como en el pasaje que acabo de citar y algunos otros $(I, 4)$. Y sin embargo el amor que se tienen no parece de hermanos, sino que incluye tanto celos como proyecto de matrimonio. ¿Qué misterio hay aquí? Jean Canavaggio escribió que el personaje del maldiciente Clodio es un «primer lector» del Persiles ${ }^{30}$, porque se plantea esto mismo (II, 5), desconfiando de las apariencias; la maliciosa Cenotia le toma el relevo $(I I, 11)$, y mucho más tarde Hipólita $(I V, 8)$. Pero la cuestión aflora varias otras veces, excediendo el campo de esos personajes. La propia Auristela la pondera: «¿Ves cuán grande es el nudo del parentesco de un hermano?, pues sobre éste tengo yo otro mayor con Periandro. ¿Ves ansimismo cuán propio es de los enamorados ser celosos?, pues con más propiedad tengo yo celos de mi hermano» $(\mathrm{I}, 23, \mathrm{p} .156)$, y diversas circunstancias vuelven a atraer la atención hacia ella (II, 2, $5,6,15 ; \mid I I, 14)$. Tendría que ser despistadísimo el lector cuyo horizonte incluyese la posibilidad de un incesto, pero hasta la sospecha se procura borrar en la profecía de Soldino: «Periandro [...], tu hermana Auristela no lo será presto, y no porque ha de perder la vida con brevedad» (III, 18, p. 396). En fin, esto es lo más cercano a una so-

29. Baena considera que la intervención del hermano de Persiles es un «pegote [...] arbitrario» (1996, p. 135); Pelorson habla exactamente de un «deus ex machina» (2003, p. 82). Esta solución podría ponerse en el marco de la dialéctica «freedom/constraint» que Armstrong-Roche encuentra en el Persiles (pp. 292-293). Valga esta nota para señalar el interés de los tres libros mencionados, a los que no se puede hacer justicia en este artículo.

30. Canavaggio, 2007. 
lución que se ofrece en los primeros tres libros de la novela. Es al comenzar el libro IV, después que Persiles y Sigismunda hablan de sus perspectivas de matrimonio, cuando por fin el narrador se aviene a decir que fueron tan discretos que «pasaron la plaza de hermanos entre todos cuantos hasta allí los habían conocido» (IV, 1, p. 415); un poco más adelante menciona «los padres de Periandro» y «los de Auristela» como distintos (p. 451). Unos capítulos después (IV, 10, 11, 12) se resuelve el enigna: la princesa Sigismunda se había criado en la corte de los padres de Persiles desde la infancia, y así eran hermanos por el trato pero no por el parentesco. Con este conocimiento, se puede entender que el matrimonio final no es escandaloso, sino apropiado.

Esta sujeción del Persiles a la «ley de lo propio» explicaría, paradójicamente, su heterogeneidad estructural. Se ha señalado la notable diferencia entre los primeros dos libros y los dos últimos, tomándola incluso como indicio de que la novela se compuso en dos etapas separadas por varios años ${ }^{31}$. Isabel Lozano-Renieblas, que analiza la estructura mediante el concepto bajtiniano de cronotopo, encuentra la unidad del Persiles en que la aventura queda absorbida en lo histórico y cotidiano con verosimilitud ${ }^{32}$. Quisiera señalar, sin embargo, que esa absorción no se da en el nivel del cronotopo ni de la acción argumental; al contrario, cuanto más se consideran estos, más resalta la heterogeneidad. Los primeros dos libros responden al cronotopo de la aventura, de tiempo y espacio abstractos, donde importan sobre todo la sucesión o simultaneidad y la distancia o coincidencia, como es propio de la novela griega de época imperial; en cambio, los libros tercero y cuarto responden al cronotopo de las aventuras en el mundo cotidiano, organizadas a lo largo de un viaje, y concretamente de un camino en torno del cual se observa la vida corriente ${ }^{33}$. Por eso, en la primera mitad de la novela Persiles y Sigismunda son sobre todo sujetos de peripecias, mientras que en la segunda son en mayor medida observadores de las de otros. La pertinencia de esas otras peripecias, muertes y matrimonios que he ido mencionando no se encuentra, por tanto, en el nivel causal del desarrollo de la acción, sino en el conceptual de su sentido. Ofrecen, como he dicho antes, un repertorio de posibilidades, con respecto a las cuales el matrimonio de Sigismunda y Persiles tiene unas relaciones determinadas, que han de tenerse en cuenta para su interpretación. Esta estructura es la que debería permitir que se reconociese esa terminación de la novela como un fin, aunque no fuera el final de la vida. Es posible, sin embargo, que ni siquiera Cervantes estuviese convencido de ello, si hacía suyo el dicho de un personaje que sienta plaza de sabio en la novela: «No la entrada, sino la salida, hace a los hombres venturosos» (III, 18, p. 393). El caso es que no dejó de añadir la coletilla: «Sigismunda [...] vivió en compañía de su esposo Persiles hasta que bisnietos le alargaron los días, pues los vio en su larga y feliz posteridad». Y ahora, sí, pone: «FIN de los trabajos de Persiles y Sigismunda» (IV, 14, p. 475).

31. Ver Avalle-Arce, 1973, pp. 199-206; pero también Lozano Renieblas, 1998, pp. 19-37, sobre la problemática más general de la datación y la unidad. 


\section{CONCLUSIONES}

Para terminar, quisiera hacer algunas observaciones sobre la relevancia del análisis del Persiles en relación con la problemática general de la poesía y ficción, entendida en términos comunicativos: cómo captar la atención y mantenerla, haciendo que se reconozca la pertinencia de lo que se dice. Como se ha visto, Cervantes introduce esa cuestión en su relato, cuando Persiles cuenta parte de sus propias andanzas; y la verdad es que no sale muy airoso: él mismo advierte que los demás se están cansando, y abrevia (II, 15), mientras que Sigismunda, habiendo experimentado lo desabrido de una larga historia, se abstiene de contar la suya (II, 21). ¿Ha tenido Cervantes mejor suerte? No diré que lo ha hecho, pero creo que lo ha pretendido hacer, con una forma narrativa que podría llamarse experimental, por la forma de reunir lo proairético y lo hermenéutico, la relevancia causal y la conceptual, la forma temporal y la espacial. Cervantes combina aquí dos maneras de narrar que había cultivado con gran acierto por separado: compárense El amante liberal y La española inglesa con Rinconete y Cortadillo. La combinación pone de manifiesto el predominio de lo conceptual sobre la acción, y por tanto nos invita a pensar la narratividad en términos cognoscitivos: un dinamismo orientado hacia un final que se capta como cumplimiento o plenificación de una trayectoria.

\section{BiBLIOgRAFÍA}

Arendt, Hannah, The Human Condition, Chicago, University of Chicago Press, 1958.

Armstrong-Roche, Michael, Cervantes' Epic Novel: Empire, Religion, and the Dream Life of Heroes in «Persiles», Toronto, University of Toronto Press, 2009.

Avalle-Arce, Juan Bautista, «Los trabajos de Persiles y Sigismunda, historia setentrional», en Suma cervantina, ed. Juan Bautista Avalle-Arce y Edward C. Riley, Londres, Tamesis, 1973, pp. 199-212.

Avalle-Arce, Juan Bautista, Nuevos deslindes cervantinos, Barcelona, Ariel, 1975.

Avalle-Arce, Juan Bautista, «La alegoría del Persiles», en Homenaje al profesor Antonio Vilanova, ed. Aldolfo Sotelo y Marta Cristina Carbonell, Barcelona, Universidad de Barcelona, 1989, vol. 1, pp. 45-56.

Baena, Julio, El círculo y la flecha: principio y fin, triunfo y fracaso del «Persiles», Chapel Hill, University of North Carolina, 1996.

Bajtín, Mijaíl, Teoría y estética de la novela, trad. H. Kriúkova y V. Cazcarra, Madrid, Taurus, 1989.

Barthes, Roland, S/Z: Essai, Paris, Seuil, 1970.

Barthes, Roland, «Analyse textuelle d'un conte d'Edgar Poe», en L'Aventure sémiologique, Paris, Seuil, 1985, pp. 329-359.

Benjamin, Walter. «Der Erzähler», en Gesammelte Schriften, II.2: Aufsätze, Essays, Vorträge, Frankfurt am Main, Suhrkamp, 1991, pp. 438-465. 
Borges, Jorge Luis, «Análisis del último capítulo del Quijote», Revista de la Universidad de Buenos Aires, 5. a época, 1, 1956, pp. 28-36.

Brooks, Peter, Reading for the Plot: Design and Intention in Narrative, Cambridge (Mass.), Harvard University Press, 1984.

Cervantes, Miguel de, Los trabajos de Persiles y Sigismunda, ed. Juan Bautista Avalle-Arce, Madrid, Castalia, 1992.

Covarrubias, Sebastián de, Tesoro de la lengua castellana o española, ed. Ignacio Arellano y Rafael Zafra, Madrid, Iberoamericana/RAE, 2006.

Cull, John T., «Death as the Great Equalizer in Emblems in Don Quixote», Hispania, 75, 1992, pp. 10-19.

Derrida, Jacques, La Carte postale: de Socrate à Freud et au-delà, Paris, Flammarion, 1980.

Fernández, Jaime, «Visión de la crítica en el siglo XX sobre la muerte de don Quijote», Edad de Oro, 25, 2006, pp. 141-155.

Frank, Joseph, The Idea of Spatial Form, New Brunswick/London, Rutgers University Press, 1991.

Galván, Luis, «Mito, interés y compromiso: arquetipos narrativos en los libros de caballerías», Rilce, 25.1, 2009, pp. 102-121.

Galván, Luis, «Exterior e interior guerra: el fundamento de la alegoría en Calderón», Anuario Calderoniano, 4, 2011, pp. 169-180.

Galván, Luis, «El motivo de la muerte en los libros de caballerías: articulación narrativa y sentido histórico», Bulletin Hispanique, 114.2, 2012, pp. 519-539.

Galván, Luis, «Acción y narración: problemas y orientaciones para la fundamentación de la narratología», en Teoría y comparatismo: tradición y nuevos espacios (Actas del I congreso internacional de ASETEL), ed. Domingo SánchezMesa y otros, Granada, Universidad de Granada, 2014, pp. 389-400.

Galván, Luis, «De la poiesis a la ficción», en Knowledge, Fiction and Interpretation, Kassel, Reichenberger, en prensa.

García Landa, José Ángel, Acción, relato, discurso: estructura de la ficción narrativa, Salamanca, Universidad de Salamanca, 1998.

Genette, Gérard, Figures III, Paris, Seuil, 1972.

Husserl, Edmund, Investigaciones lógicas, Madrid, Alianza, 2006, 2 vols.

Lo Ré, Anthony G., «The Three Deaths of Don Quixote: Comments in Favor of the Romantic Critical Approach», Cervantes. Bulletin of the Cervantes Society of America, 9, 1989, pp. 21-41.

Lozano Renieblas, Isabel, Cervantes y el mundo del «Persiles», Alcalá de Henares, Centro de Estudios Cervantinos, 1998. 
Mann, Thomas, Meerfahrt mit don Quijote, Frankfurt am Main, Fischer, 2002.

Nerlich, Michael, El «Persiles» descodificado o la «Divina Comedia» de Cervantes, trad. Jesús Munárriz, Madrid, Hiperión, 2005.

Pelorson, Jean-Marc, El desafío del «Persiles»,Toulouse, Presses Universitaires du Mirail, 2003

Pozuelo Yvancos, José María, Poética de la ficción, Madrid, Síntesis, 1993.

Ricoeur, Paul, Soi-même comme un autre, Paris, Seuil, 1990.

Ryan, Marie-Laure, «Toward a Definition of Narrative», en The Cambridge Companion to Narrative, David Herman (ed.), Cambridge, Cambridge University Press, 2007, pp. 22-35.

Sternberg, Meir, «Universals of Narrative and their Cognitivist fortunes, 1», Poetics Today, 24.2, 2003a, pp. 297-395.

Sternberg, Meir, «Universals of Narrative and their Cognitivist fortunes, Il», Poetics Today, 24.3, 2003b, pp. 517-638.

Todorov, Tzvetan, Poétique, Paris, Seuil, 1973. 